\title{
Captive Power Plant Selection for Pakistan Cement Industry in Perspective of Current Energy Crises: A Fuzzy-AHP Approach
}

\author{
HAFIZ MUHAMMAD KHURRAM ALI*, AMIR SULTAN*, AND BAKHT BAHADUR RANA** \\ RECEIVED ON 11.02.2016 ACCEPTED ON 11.05.2016
}

\begin{abstract}
Based on the prevailing energy crisis, it is reasonable for the Cement industry of Pakistan to look for alternate sources of electricity generation. The decision of selecting a CPP (Captive Power Plant) depends on a broad variety of parameters which may be conflicting to each other. A comparative evaluation of these CPP's should be helpful for industry, particularly if the applied methodology can handle with the real world ambiguities and imprecisions associated with the data pools and expert opinions. This paper utilizes an F-AHP (Fuzzy Analytical Hierarchy Process) based multi-attribute framework to prioritize the affecting parameters and assign rankings to the CPP alternatives. The CPP's recommended by experts for this study are RDF-CPP (Refused Derived Fuel CPP), CF-CPP (Coal Fired CPP) and WHR-CPP(Waste Heat Recovery CPP). The factors affecting the decision of selecting the optimum CPP are prioritized by the experts using our F-AHP approach. Real world quantitative data is extracted from different online resources and financial reports of cement companies in Pakistan. The F-AHP model is flexible enough to deal with a variety of inputs including qualitative scales, crisp values and standard fuzzy numbers. The model is solved and a sensitivity analysis is performed in respective software. This study shows that non-conventional CPPs are highly demanded for cement industry in Pakistan and while selecting these CPPs, management gives high priority to factors like 'automation' and 'environment' whereas associated 'initial cost' is not given much weight in decision making. In concluding ranking list, WHR-CPP is at the top and CF-CPP is at the bottom. This study may facilitate decision makers of cement industry in Pakistan and international CPP manufacturers alike in their forthcoming strategic decisions.
\end{abstract}

Key Words: Fuzzy Analytical Hierarchy Process, Multi-Criteria Decision Making, Captive Power Plants, Cement Industry.

\section{INTRODUCTION}

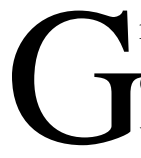

rowth and development of any country highly depends on uninterrupted supply of energy which is affordable and reliable. This challenge becomes more serious when it comes to developing countries like Pakistan which are facing uphill task to meet ever increasing energy needs for sustainable development. Oil, natural gas, hydro, nuclear and coal are the chief sources of electricity in Pakistan.

Corresponding Author: (E-Mail: khurram.ali@uetraxila.edu.pk)

* Department of Mechatronic Engineering, University of Engineering \& Technology, Taxila, Sub-Campus Chakwal.

** Glass \& Ceramics Research Centre, PCSIR Labs. Lahore.

Mehran University Research Journal of Engineering \& Technology, Volume 36, No. 4, October, 2017 [p-ISSN: 0254-7821, e-ISSN: 2413-7219] 
Electricity is not only indispensable for domestic use but is equally important, if not more, for industry, agriculture, transport, etc. Increase in electricity supply could not stay even with the growing demand as a result of increased industrialization and urbanization in Pakistan. The gap between demand and supply in the country is likely to continue by year 2020 [1].

Industry is the $2^{\text {nd }}$ largest energy utilizing sector in Pakistan which consumes 38\% of the total energy and is expected to grow further in the years to come [2]. Most of the industries are running at less than $50 \%$ capacity due to energy crises. In industrial sector, cement industry is the key entity which has very important role in building Pakistan and at the same time since it is the tenth major export item it earns a significant amount of foreign exchange for the country. Since this present study focuses on decision making in the energy management of cement plants further discussion will be restricted to cement industry in Pakistan.

Pakistan is one of the top twenty cement producing countries with installed capacity in excess of 44 million tons per year. It is ranked eighth in cement exporting countries of the world. Modest estimates of about $8 \%$ growth in next five years demand cement industry for further increase in production capacity [3]. Production of cement is one of the extremely energy exhaustive process which consumes $110-120 \mathrm{kWh}$ of electricity per ton of cement. Fuel and electricity combined together make up $74 \%$ of the all expenditures incurred on production of cement [4].Total electricity consumption of cement industry in Pakistan is about $720 \mathrm{MW}$ for which it has to rely on electricity from national grid which is costly and unreliable [5]. In order to deal with the present energy crises, cement industry in Pakistan needs to use CPP to generate electricity for its use. Though some cement plants have already started CPPs but these are still dependent on use of conventional fuels such as oil and natural gas which are not only expensive but are also depleting fast.
The top management has therefore started considering non-conventional options of CPPs such as coal fired, waste heat recovery and waste to energy/RDF.

Coal is the second largest source of energy having about $27.3 \%$ share in the global primary energy mix [6]. Coal based plants of up to $50 \mathrm{MW}$ cost about 1.2 1.5 million US\$/MW and can be installed within 2 years. Pakistan has approximately 186 billion tons of coal (around 1/5 of the world's total known coal reserves) but its share in energy mix is $0.1 \%$ when it comes to electric power leaving huge potential for electricity generation [6].

Another area which has great potential for power generation in cement industry is heat of exhaust gases. By this way cement operating efficiency of plant is improved making production cost even more competitive. Some cement plants have already introduced WHRS (Waste Heat Recovery System) whereas others are considering this option [7].

RDF is obtained by efficiently removing inert fractions from the waste and turns it into valuable alternative fuel. In Pakistan, about 3,000 MW of electricity can be generated from the municipal waste. Cement factories in Pakistan are already planning to install RDF based plants [8].

The current scenario of energy needs of Pakistan cement industry have compelled the top managements to install the non-conventional CPP's. Most of them are considering the three options discussed above because of abundant availability of respective fuels and other competitive business advantages. There is a very strong investment potential for global firms which manufacture and supply the equipment of mentioned CPP's. To understand the actual market demands, there is an inevitable need to conduct an MCDM (Multi-Criteria Decision Making) based study which defines the current cement industry preferences by taking into account the real world ambiguities.

Mehran University Research Journal of Engineering \& Technology, Volume 36, No. 4, October, 2017 [p-ISSN: 0254-7821, e-ISSN: 2413-7219] 


\section{$1.1 \quad$ Fuzzy-AHP Based CPP Selection}

Despite its broader applications and simplicity in concept, the stand alone AHPas used by Gohar et. al. [9]cannot satisfactorily handle the imprecision and uncertainty in available data and in decision-maker's preferences. Human judgments whether they are quantitative or qualitative have some inherent uncertainty in practical scenarios due to different personal perceptions. Experts might also be reluctant to assign exact numerical values while comparing parameters. In MCDM, evaluation criteria are both subjective and quantitative depending upon the nature. The consulted databases also include certain imprecisions as some approximation might also be involved in preparation of such database. Good decisionmaking models should be able take this natural fuzziness into account to avoid misleading results. The alone AHP cannot precisely handle this inherent vagueness and uncertainty thus requiring the integrated Fuzzy-AHP $[10,11]$.

Different fuzzy-AHP methods introduced had been systematically applied for the alternative selection problems with imprecise or vague information using the fuzzy theory integrated with hierarchical structure analysis. Laarhoven and Pedrycs [12] implemented TFN's (Triangular Fuzzy Numbers) to represent the expert's assessment with respect to each parameter and offered an algorithm as an extension of AHP. The study was followed by Buckley's geometric mean method [13]. Afterwards, Chang introduced a TFNs based synthetic extent analysis method which was utilized by a large number of researchers in different F-AHP applications [14-16]. According to arguments presented by Hsu et. al. [17], the TFN's can be preferred in questionnaire reports over others like square and trapezoidal etc. Meanwhile, Wang et. al. [18] raised some reservations about Chang's method and Calabrese et. al. [19] thus introduced a modified row sum method which is partially utilized in this study.

Broader applications of F-AHP in different domains are reported in literature. A few of them, though not in very large number, have focused on problems related to energy sector as well. Lee et. al. [20] utilized a FuzzyAHP hybrid model to explore and prioritize five factors for energy R\&D resources. Thermal power plants were the focus of the research by Choudharyand Shankar [21]. Kahraman and Kaya [22] also implemented Fuzzy based MCDM methodology for selection among energy alternatives. Some of the researchers have emphasized on MCDM based solutions of renewable energy problems. Tasriand Susilawati [23] compared the alternatives like wind energy, solar, biomass, geothermal, hydro-power etc. Eunnyeong Heo et. al. [24] used FAHP to assess the importance of factors for renewable energy circulation program.

There are slight variations in different F-AHP modeling approaches applied in energy sector. However, there are very rare models which are flexible enough to deal all kinds of fuzzy and crisp data. We are unable to find any F-AHP approach in literature which focuses on the CPP selection decisions particularly in perspective of Pakistan. The decision of selecting a CPP alternative depends on different parameters which are sometimes conflicting to each other. We have to screen out the most critical factors and then assign concerned priorities to them. The F-AHP approach presented in this study can handle with a variety of data whether it is in the form of qualitative opinions of experts, numerical weights, crisp values from data bases or well defined fuzzy numbers.

Next section presents the F-AHP methodology utilized in this study. Developed models are solved in section 3 using the real world data. The paper concludes in section 4. 


\section{THE METHODOLOGY OF THE STUDY}

In this study, we utilize a modified F-AHP based hybrid procedure presented by $[25,26]$ comprehendedin Fig. 1 as a framework.

\subsection{Phase-1: Initialization}

Step-1: Construct the AHP hierarchy

Step-2: Defining the Variables: Suppose there are ' $\mathrm{N}$ ' potential alternatives named $A_{1}, A_{2}, A_{3} \ldots \ldots \ldots A_{N}$ and there are 'I' parameters or main criteria $\mathrm{C}_{1}, \mathrm{C}_{2}, \mathrm{C} \ldots \ldots \ldots . . \mathrm{C}_{\mathrm{I}}$ and ' $\mathrm{J}$ ' sub criteria under the main criteria " $\mathrm{i}$ ” i.e. $\mathrm{C}_{\mathrm{i} 1}, \mathrm{C}_{\mathrm{i} 2}$ ' $\mathrm{C}_{\mathrm{i} 3} \ldots \ldots \mathrm{C}_{\mathrm{iJ}}$ while $1 \leq \mathrm{n} \geq \mathrm{N}, 1 \leq \mathrm{i} \geq \mathrm{I}$. Suppose further that $\widetilde{\mathrm{W}}_{\mathrm{i}}=\left(\mathrm{l}_{\mathrm{i}}, \mathrm{m}_{\mathrm{i}}, \mathrm{u}_{\mathrm{i}}\right)$ are the fuzzy importance weights for main parameters $C_{i}$ and $\widetilde{W}_{i j}=\left(l_{i j}, m_{i j}, u_{i j}\right)$ are the fuzzy priority weights for sub parameters.The experts will assess all the parameters to assign priority weights.

Step-3: Define the linguistic variables using standard TFN's to assign fuzzy priority weights to parameters or alternatives.

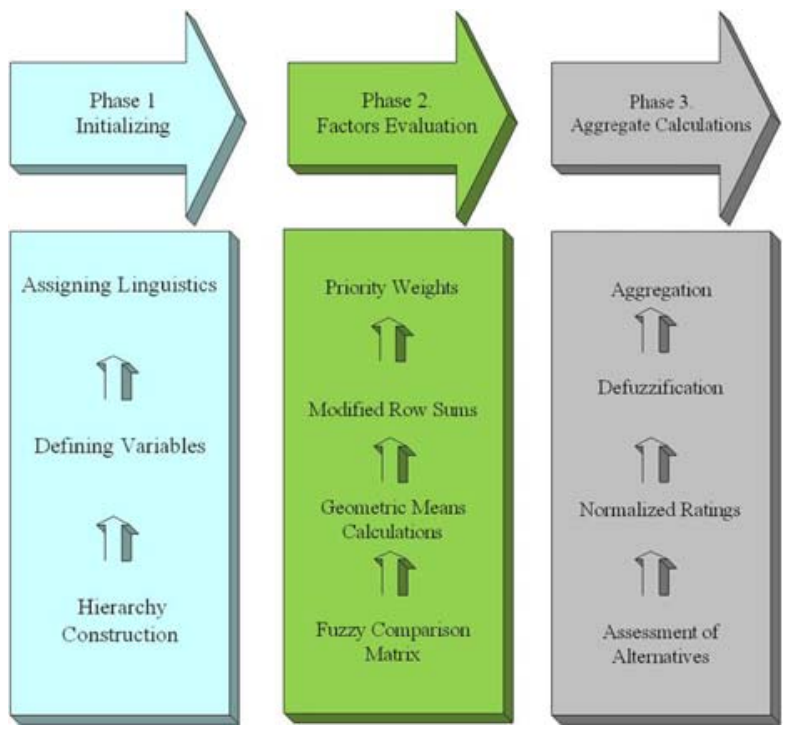

FIG. 1. SHOWING PHASES OF FUZZY-AHP PROCESS
Step-4: Using linguistic variables, define the alternative ratings.

\subsection{Phase-2: Parameter Evaluations}

It includes the following steps:

Step-1: Collect the linguistic or numerical pairwise comparisons of all the factors from concerned experts. If required, convert the linguistic terms into TFN's. The recorded judgments are organized in fuzzy comparison matrix as in Equation (1):

$\tilde{\mathrm{A}}=\left(\tilde{\mathrm{a}}_{\mathrm{ij}}\right)_{\mathrm{nxn}}=\left[\begin{array}{cccc}(1,1,1) & \left(\mathrm{l}_{12}, \mathrm{~m}_{12}, \mathrm{u}_{12}\right) & \ldots & \left(\mathrm{l}_{1 \mathrm{n}}, \mathrm{m}_{1 \mathrm{n}}, \mathrm{u}_{1 \mathrm{n}}\right) \\ \left(\mathrm{l}_{21}, \mathrm{~m}_{21}, \mathrm{u}_{21}\right) & (1,1,1) & \ldots & \left(\mathrm{l}_{2 \mathrm{n}}, \mathrm{m}_{2 \mathrm{n}}, \mathrm{u}_{2 \mathrm{n}}\right) \\ \vdots & \vdots & \ldots & \vdots \\ \left(\mathrm{l}_{\mathrm{n}}, \mathrm{m}_{\mathrm{n} 1}, \mathrm{u}_{\mathrm{n} 1}\right) & \left(\mathrm{l}_{\mathrm{n} 2}, \mathrm{~m}_{\mathrm{n} 2}, \mathrm{u}_{\mathrm{n} 2}\right) & \ldots & (1,1,1)\end{array}\right]$

where

$\widetilde{\mathrm{a}}_{\mathrm{ij}}=\left(1_{\mathrm{ij}}, \mathrm{m}_{\mathrm{ij}}, \mathrm{u}_{\mathrm{ij}}\right)=\widetilde{\mathrm{a}}_{\mathrm{ij}}^{-1}=\left(\frac{1}{\mathrm{u}_{\mathrm{ji}}}, \frac{1}{\mathrm{~m}_{\mathrm{ji}}}, \frac{1}{\mathrm{l}_{\mathrm{ji}}}\right)$ and $\mathrm{i}, \mathrm{j}=1,2,3, \ldots \mathrm{n} ; \mathrm{i} \neq \mathrm{j}$ and the matrix is a $\widetilde{\mathrm{A}}$ symmetric and square matrix.

Step-2: Defuzzify all the members of the comparison matrix by using the canonical method [27] defined in Equation (2) so that we can have a consistency check,

$\mathrm{a}_{\mathrm{ij}}=\frac{1}{6}\left(\mathrm{l}_{\mathrm{ij}}+4 \mathrm{~m}_{\mathrm{ij}}+\mathrm{u}_{\mathrm{ij}}\right)$

Step-3: Check the consistency of the collected data using standard models.

Step-4: Revert back to the fuzzy matrix. In case of multiple experts, we need to aggregate their decisions. Calculate the geometric means of TFN's collected by using Buckley's”Column Vector Geometric Mean Method” presented in Equation (3).

$\tilde{\mathrm{Z}}_{1}=\left(\mathrm{a}_{\mathrm{i} 1} \otimes \mathrm{a}_{\mathrm{i} 2} \otimes \mathrm{a}_{\mathrm{i} 3} \ldots . . \otimes \mathrm{a}_{\mathrm{in}}\right)^{1 / \mathrm{n}}$

Step-5: For each row of $\tilde{A}$ calculate the respective relative row sums according to Chang's Extent Analysis method [28] as shown in Equation (4): 
$\widetilde{R} \tilde{S}_{i}=\sum_{j=1}^{n} a_{i j}=\left(\sum_{j=1}^{n} 1_{i j}, \sum_{j=1}^{n} m_{i j}, \sum_{j=1}^{n} u_{i j}\right) i=1, \ldots n$

Calculate the normalized row sum using modified method of calculations introduced by Calabrese [19] using the Wang and Elhag's correction [29] using in Equation (5).

$\tilde{W}_{i}=\frac{R S_{i}}{\sum_{j=1}^{n} R \tilde{S}_{j}}=\left(\frac{\sum_{j=1}^{n} 1_{i j}}{\sum_{j=1}^{n} 1_{1 j}+\sum_{k=1, k \neq 1}^{n} \sum_{j=1}^{n} u_{k j}}, \frac{\sum_{j=1}^{n} m_{i j}}{\sum_{k=1, k \neq 1}^{n} \sum_{j=1}^{n} m_{k j}}, \frac{\sum_{j=1}^{n} u_{i j}}{\sum_{j=1}^{n} u_{i j}+\sum_{k=1, k \neq j}^{n} \sum_{j=1}^{n} 1_{k j}}\right)$

Calculate the row sums by using this modified Equation

(5) resulting in fuzzy weights for all parameters summarized in Equation (6):

$\tilde{W}_{\mathrm{i}}=\left(\mathrm{l}_{\mathrm{i}}, \mathrm{m}_{\mathrm{i}}, \mathrm{u}_{\mathrm{i}}\right), \mathrm{i}=1 \ldots \mathrm{n}$

Step-6: Normalize the weights by using in Equation (7):

$\tilde{W}_{\mathrm{i}}=\frac{\tilde{\mathrm{W}}_{\mathrm{i}}}{\sum_{\mathrm{j}=1}^{\mathrm{W}} \tilde{\mathrm{W}}_{\mathrm{isj}}}$

Where

$\sum_{\mathrm{i}=1}^{\mathrm{I}} \quad \mathrm{W}_{\mathrm{i}}=1, \sum_{\mathrm{j}=1}^{\mathrm{j}} \quad \mathrm{W}_{\mathrm{ij}}=1$

Step-7: Using Equations (5 and 6), determine the local priority weight of each criteria and sub criteria by defuzzifying $\widetilde{\mathrm{W}}_{i}$ using canonical method. The weight vector is therefore formed as follows:

$$
\begin{aligned}
& \mathrm{W}=\left[\mathrm{W}_{1} \mathrm{xW}_{11}, \mathrm{~W}_{1} \mathrm{xW}_{12} \ldots . . \mathrm{W}_{1} \mathrm{xW}_{1 \mathrm{l}} \ldots . . \mathrm{W}_{\mathrm{i}} \mathrm{xW} \mathrm{W}_{\mathrm{i} 1} \ldots . .\right. \\
& \left.\mathrm{W}_{\mathrm{i}} \mathrm{xW}_{\mathrm{i} 2} \ldots \ldots \mathrm{W}_{\mathrm{i}} \mathrm{xW}_{\mathrm{ij}} \ldots \ldots \mathrm{W}_{\mathrm{I}} \mathrm{xW}_{\mathrm{I} 1}, \mathrm{~W}_{\mathrm{I}} \mathrm{xW}_{12} \ldots \ldots \mathrm{W}_{1} \mathrm{xW}_{\mathrm{Ij}}\right] \\
& \mathrm{W}=\left[\mathrm{W}_{111}, \mathrm{~W}_{112} \ldots \mathrm{W}_{11 \mathrm{j}} \ldots . . \mathrm{W}_{\mathrm{ii1}}, \ldots \ldots \mathrm{W}_{\mathrm{ii2}} \ldots \ldots\right. \\
& \left.\mathrm{W}_{\mathrm{iij}} \cdots . . \mathrm{W}_{\mathrm{II} 1} \ldots . . \mathrm{W}_{\mathrm{II} 2} \cdots . . \mathrm{W}_{\mathrm{IIJ}}\right]
\end{aligned}
$$

\subsection{Phase-3: Aggregate Calculations}

It includes following steps.

Step-1: Alternative assessments under objective parameters:

Let $\widetilde{\mathrm{R}}_{\mathrm{ijn}}=\left(\mathrm{l}_{\mathrm{ijn}}^{\mathrm{o}}, \mathrm{m}_{\mathrm{ijn}}^{\mathrm{o}}, \mathrm{u}_{\mathrm{ijn}}^{0}\right)$ be the fuzzy ratings assigned to alternative ' $A_{n}$ ' under objective sub-parameters ' $C_{i j}$ '. Since different databases are used to assign these ratings, they should be first transformed into dimensionless values or ratings to make them compatible with linguistic ratings assigned to subjective criteria. For this purpose procedure introduced by Chou and $\mathrm{Yu}$ [30] has been adopted here. The parameter ratings are either desirables or undesirables. When dealing with desirable parameters an alternative with higher rating is preferable as is the case of profits or sales. Scenario is reversed when dealing with undesirable parameters like costs. We can use the following Equations $(9,10)$ for transformation of the fuzzy ratings [30].

$$
\tilde{\mathrm{R}}_{\mathrm{ijn}}=\left\{\frac{\tilde{\mathrm{R}}_{\mathrm{ijn}}^{\mathrm{o}}}{\max _{\mathrm{i}}\left\{\mathrm{u}_{\mathrm{ijn}}^{0}\right\}}\right\} \times 5
$$

Where $\max _{\mathrm{i}}\left\{\left\{_{\mathrm{ijn}}\right\}>0\right.$ and $\widetilde{\mathrm{R}}_{\mathrm{ijn}}$ is the transformed fuzzy rating of objective fuzzy benefit (desirable parameters) $\widetilde{R}_{\text {ijn }}^{0}$. The larger value of objective fuzzy benefit $\widetilde{R}_{\text {ijn }}^{0}$ makeslarger.

$$
\widetilde{\mathrm{R}}_{\mathrm{ijn}}=\left\{\frac{\min _{\mathrm{i}}\left\{\mathrm{l}_{\mathrm{ijn}}^{\mathrm{o}}\right\}}{\widetilde{\mathrm{R}}_{\mathrm{ijn}}^{\mathrm{o}}}\right\} \times 5
$$

Whereis the transformed fuzzy ratings of objective fuzzy cost. The larger value of objective fuzzy benefit makes smaller.

Step-2: Alternative assessments under subjective parameters: Experts assess the alternatives for subjective criteria using pairwise comparisons for each parameter. Calculate the normalized fuzzy ratings using Equations.

Step-3: Letbe the fuzzy ratings calculated for alternative ' $A_{n}$ ' under subjective sub-criteria ' $C_{i j}$ ' in step 2. Constitute the fuzzy rating matrix based on the ratings obtained in above two steps. Letbe the fuzzy rating matrix which is concisely expressed in matrix format in Equation (11): 


$$
\tilde{\mathrm{M}}=\left[\begin{array}{cccc}
\left(\widetilde{\mathrm{R}}_{111}\right) & \left(\widetilde{\mathrm{R}}_{121}\right) & \cdots & \left(\widetilde{\mathrm{R}}_{1 \mathrm{IJ} 1}\right) \\
\left(\widetilde{\mathrm{R}}_{112}\right) & \left(\widetilde{\mathrm{R}}_{122}\right) & \cdots & \left(\widetilde{\mathrm{R}}_{1 \mathrm{IJ}}\right) \\
\vdots & \vdots & \ddots & \vdots \\
\left(\widetilde{\mathrm{R}}_{11 \mathrm{~N}}\right) & \left(\widetilde{\mathrm{R}}_{12 \mathrm{~N}}\right) & \cdots & \left(\widetilde{\mathrm{R}}_{\mathrm{IJN}}\right)
\end{array}\right]
$$

Elements of the matrix include both subjective and objective parameters.

Step-4: Using the canonical method [27], defuzzify all elements of the fuzzy rating matrix .Thus we obtain the matrix ' $M$ ' represented in Equation (12):

$$
\mathrm{M}=\left[\begin{array}{cccc}
\mathrm{R}_{111} & \mathrm{R}_{121} & \cdots & \mathrm{R}_{\mathrm{IJ1}} \\
\mathrm{R}_{112} & \mathrm{R}_{122} & \cdots & \mathrm{R}_{\mathrm{IJ2}} \\
\vdots & \vdots & \ddots & \vdots \\
\mathrm{R}_{11 \mathrm{~N}} & \mathrm{R}_{12 \mathrm{~N}} & \cdots & \mathrm{R}_{\mathrm{IJN}}
\end{array}\right]
$$

Step-5: Finally multiply the rating matrix ' $M$ ' with weight vector ' $W$ ' using Equation (13) to obtain the aggregate weights for the alternative countries.

$$
\mathrm{R}=\left[\begin{array}{cccc}
\mathrm{R}_{111} & \mathrm{R}_{121} & \cdots & \mathrm{R}_{\mathrm{IJ} 1} \\
\mathrm{R}_{112} & \mathrm{R}_{122} & \cdots & \mathrm{R}_{\mathrm{IJ} 2} \\
\vdots & \vdots & \ddots & \vdots \\
\mathrm{R}_{11 \mathrm{~N}} & \mathrm{R}_{12 \mathrm{~N}} & \cdots & \mathrm{R}_{\mathrm{IJN}}
\end{array}\right] \times\left[\begin{array}{c}
\mathrm{W}_{111} \\
\mathrm{~W}_{112} \\
\vdots \\
\mathrm{W}_{\mathrm{IJL}}
\end{array}\right]=\left[\begin{array}{c}
\mathrm{R}_{1} \\
\mathrm{R}_{2} \\
\vdots \\
\mathrm{R}_{\mathrm{N}}
\end{array}\right]
$$

\section{DATA SPECIFIC SOLUTIONS OF F-AHP MODELS}

The three CPP's discussed in introduction section are the alternatives for our study. The factors affecting this decision of CPP selection are explored from the literature and shortlisted with the consent of concerned cement industry managers. The analysis is made for $15 \mathrm{MW}$ power plants required for the electrification of the cement plants. The factors are shown in the standard AHP hierarchy presented in Fig. 2.

More than fifteen experts from different industries of Pakistan had been approached. They provided their opinions in the form of numeric scales, qualitative terms or in fuzzy numbers whichever was convenient for them.

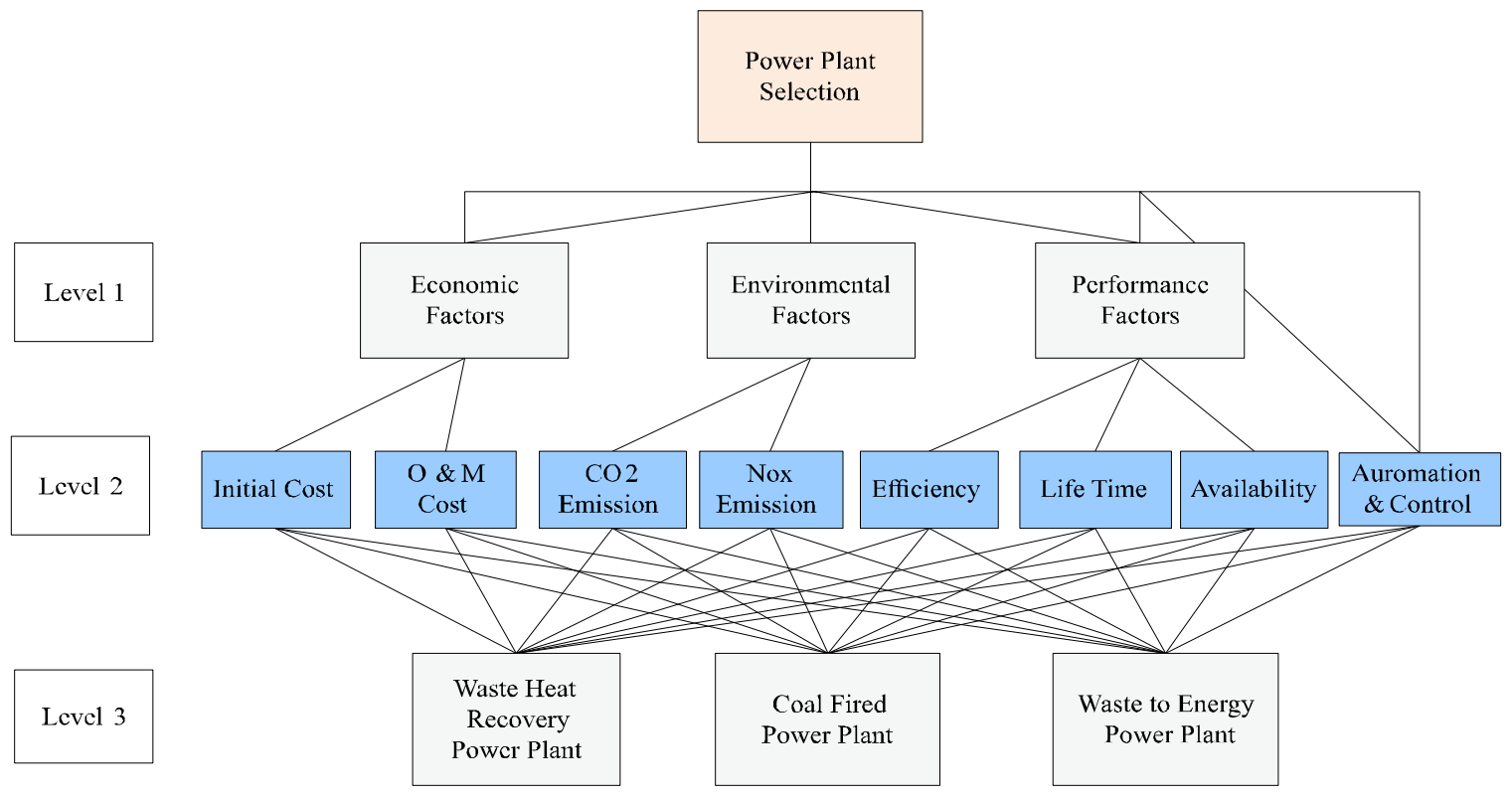

FIG. 2. HIERARCHY OF THE PROBLEM

Mehran University Research Journal of Engineering \& Technology, Volume 36, No. 4, October, 2017 [p-ISSN: 0254-7821, e-ISSN: 2413-7219] 
After checking the respective inconsistencies the collected data has been converted to standard TFN's as defined in the F-AHP methodology. Geometric means of these fuzzy numbers are calculated using Equation (3). For example the geometric mean of expert opinions for fuzzy pairwise comparison between 'Economic' and 'Environmental' is calculated below:

$\tilde{Z}_{i}=\left[\begin{array}{l}(1.0,2.0,30) \otimes(0.200,0.2 \Phi, 0.333) \otimes(0.33,0.501 .0) \otimes \\ (0.333,0.51) \otimes(3,04,0,5) \otimes(1,2,3) \otimes(0.125,0.18,0.167) \otimes \\ (0.333,0.5(0,1.00) \otimes(3,4,5) \otimes(0.111,0.13,0.143) \otimes \\ (1,1,1) \otimes(0.11,0.110 .11) \otimes(1,1,1) \otimes(0.33,0.501 .0) \otimes(0.125,0.18,0.167\end{array}\right]^{-1 / 5}$

Using the fuzzy arithmetic, $\tilde{\mathrm{z}}_{\mathrm{l}}=(0.577,1.000,1.732)$

All the geometric means of main and sub-factors are calculated using same procedure. Fuzzy geometric means of main factors are shown in Table 1.

Using Equation (5) row sums of above calculated geometric means of main and sub factors are calculated. Normalized row sums are calculated using Equation (7). For example row sum of Economic factors is calculated as:

$\widetilde{R} \widetilde{S}_{i}=\left[\begin{array}{c}(1,1,1) \otimes(0.577,1.000,1.732) \otimes \\ (0.354,0.378,0.408) \otimes(0.136,0.158,0.189)\end{array}\right]$

Using the fuzzy arithmetic,

$\widetilde{R} \widetilde{S}_{i}=(2.067,2.536,3.329)$

Normalized row sum $=[(2.067 / 16.394,2.536 / 13.909,3.329 /$
$11.929)]=(0.112,0.154,0.218)$

Table 2 shows the row sum and normalized row sum of main factors.

Canonical method is used to get defuzzified weights of main and sub factors. Geometric means, row sum, normalized row sum and fuzzy weights of subjective factor 'automation and control' with respect to alternatives are shown in Table 3.

The fuzzy ratings of objective sub factors with respect to alternatives are then calculated using Equations (9-10) for desirable and undesirable factors respectively. Then defuzzification is done by canonical method. As an example of undesirable factor consider the sub-factor "Investment cost" under the main factor "Economic Factors". A lower value means that the captive power plant is at a higher place in the ranking list which makes the power plant a comparatively stronger candidate. Using Equation (10):

$$
\tilde{\mathrm{R}}_{\mathrm{ijn}}=\left\{\frac{\min _{\mathrm{i}}\left\{l_{\mathrm{ijn}}^{\mathrm{o}}\right\}}{\widetilde{\mathrm{R}}_{\mathrm{ijn}}^{\circ}}\right\} \times 5=\left[5 *\left(\frac{27}{60}\right), 5 *\left(\frac{27}{45}\right), 5 *\left(\frac{27}{30}\right)\right]=(2.25,3,4.5)
$$

Take 'Efficiency', a sub-factor of "Performance”, as an instance of desirable factors. So using Equation (9):

$$
\tilde{\mathrm{R}}_{\mathrm{ijn}}=\left\{\frac{\tilde{\mathrm{R}}_{\mathrm{ijn}}^{\mathrm{o}}}{\max _{\mathrm{i}}\left\{\mathrm{u}_{\mathrm{ijn}}^{\mathrm{o}}\right\}}\right\} \times 5=\left[5 *\left(\frac{20}{48}\right), 5 *\left(\frac{25}{48}\right), 5 *\left(\frac{30}{48}\right)\right]=(2.08,2.6,3.13)
$$

The calculated fuzzy weights and normalized weights are shown in Appendix-I.

TABLE 1. FUZZY GEOMETRIC MEANS OF MAIN FACTORS

\begin{tabular}{|c|c|c|c|c|}
\hline & Economic & Environmental & Performance & Automation \\
\hline Economic & $(1.000,1.000,1.000)$ & $(0.577,1.000,1.732)$ & $(0.354,0.378,0.408)$ & $(0.136,0.158,0.189)$ \\
\hline Environmental & $(1.255,1.724,2.280)$ & $(1.000,1.000,1.000)$ & $(0.354,0.378,0.408)$ & $(0.136,0.158,0.189)$ \\
\hline Performance & $(0.978,1.091,1.215)$ & $(1.039,1.376,1.761)$ & $(1.000,1.000,1.000)$ & $(0.750,0.819,0.902)$ \\
\hline Automation & $(1.565,1.950,2.534)$ & $(0.854,1.047,1.234)$ & $(1.108,1.047,1.234)$ & $(1.000,1.000,1.000)$ \\
\hline
\end{tabular}

Mehran University Research Journal of Engineering \& Technology, Volume 36, No. 4, October, 2017 [p-ISSN: 0254-7821, e-ISSN: 2413-7219] 


\section{RESULTS AND DISCUSSION}

The calculations for weights of the criteria and alternatives, as discussed above, have been performed in MS Excel ${ }^{\circledR}$ sheets. The defuzzified and normalized weights can now be considered as inputs for an ordinary AHP problem represented by the model in Equation (13). We, therefore, are now able to utilize the AHP software Expert Choice ${ }^{\circledR}$ where the AHP model is normally developed and solved. The results can be divided into two categories; priority weights of the factors and rankings of the alternatives. Priorities calculated for the main factors are shown in Fig. 3(a-d).

Results show that 'automation and control' factor tops the list whereas 'economic factors' has the least priority for management of cement industry in their decision making. This is indeed very interesting and attractive from the perspective of the international investors. Energy crises in Pakistan has enforced decision makers and senior managemnt of the cement industry to look for solutions. Study shows that there is high demand for automated, evironmentally friendly and highly effcient CPPs, irrespective of their cost. Though 'economic factor' has least priority, 'operations and maintenance costs' in its sub-factors has higher priority weight as compared to initial cost. There is not much difference shown in local priority weights of sub-factors of 'environment' and 'performance' factors.

Overall ranking of the CPPs is shown in Fig. 4. WHR-CPP has got the clear lead in the ranking. RDF-CPP and CFCPP are respectively second and third in the ranking having not much difference between the two.

TABLE 2. ROW SUM AND NORMALIZED ROW SUM OF MAIN FACTORS

\begin{tabular}{|c|c|c|c|c|}
\hline Main Factors & Row Sum & Normalized Row Sum & Defuzzified Weight & Normalized Weight \\
\hline \multicolumn{5}{|c|}{ Main Factors } \\
\hline Economic & $(2.067,2.536,3.329)$ & $(0.112,0.154,0.218)$ & 0.158 & 0.157 \\
\hline Environmental & $(3.634,4.405,5.413)$ & $(0.203,0.268,0.343)$ & 0.268 & 0.268 \\
\hline Performance & $(3.763,4.286,4.879)$ & $(0.202,0.2610,323)$ & 0.259 & 0.259 \\
\hline Automation & $(4.527,5.218,6.102)$ & $(0.249 .0 .317,0.329)$ & 0.316 & 0.316 \\
\hline \multicolumn{5}{|c|}{ Sub-Factors } \\
\hline O\&M Cost & $(2.576,2.954,3.437)$ & $(0.662,0.661,0.709)$ & 0.661 & 0.661 \\
\hline Investment Cost & $(1.410,1.512 .1 .635)$ & $(0.291,0.339,0.388)$ & 0.339 & 0.339 \\
\hline CO2 Emission & $(1.638,1.750,1.923)$ & $(0.389,0.429 .0 .480)$ & 0.431 & 0.431 \\
\hline NOx Emission & $(2.083,2.333,2.567)$ & $(0.519,0.571,0.610)$ & 0.569 & 0.569 \\
\hline Efficiency & $(3.080,3.417,3.781)$ & $(0.319,0.368,0.418)$ & 0.368 & 0.368 \\
\hline Life Time & $(2.902,3.287,3.739)$ & $(0.305,0.354,0.407)$ & 0.355 & 0.354 \\
\hline Availability & $(2.362,2.578,2.847)$ & $(0.239,0.278,0.322)$ & 0.279 & 0.278 \\
\hline
\end{tabular}

TABLE 3. GEOMETRIC MEANS OF PAIR WISE COMPARISONS OF SUBJECTIVE FACTOR

\begin{tabular}{|c|c|c|c|c|c|c|c|}
\hline & CF & WHR & RDF & Row Sum's & Normalized & $\begin{array}{c}\text { Defuzzified } \\
\text { Weight }\end{array}$ & $\begin{array}{c}\text { Normalized } \\
\text { Weight }\end{array}$ \\
\hline CF & $(1.000,1.000,1.000)$ & $(0.317,0.398,0.555)$ & $(0.490,0.7043,1.105)$ & $(1.807,2.101,2.660)$ & $(0.153,0.203,0.289)$ & 0.209 & 0.208 \\
\hline WHR & $(1.802,2.517,3.158)$ & $(1.000,1.000,1.000)$ & $(1.355,1.7472,2.062)$ & $(4.159,5.265,6.221)$ & $(0.392,0.508,0.597)$ & 0.504 & 0.504 \\
\hline RDF & $(0.904,1.419,2.038)$ & $(0.484,0.572,0.737)$ & $(1.000,1.000,1.000)$ & $(2.390,2.992,3.777)$ & $(0.212,0.289,0.388)$ & 0.293 & 0.291 \\
\hline
\end{tabular}

Mehran University Research Journal of Engineering \& Technology, Volume 36, No. 4, October, 2017 [p-ISSN: 0254-7821, e-ISSN: 2413-7219] 
To have a detailed investigation of results we need to discuss the alternative rankings with respect to influencing criteria as summarized in Fig. 5.

Considering 'environmental' and 'automation and control' factors, WHR-CPP has clear advantage over its competitors. In respect of 'economic factors' it compares almost similar to RDF-CPP and marginally lower than CFCPP. RDF-CPP ranks higher than CF-CPP and lower than WHR-CPP in all factors except for 'performance' for which it ranks the lowest. CF-CPP ranks lowest in the list and is most harmful to the environment.
To have a sensitivity analysis, the input priorities of factors are hypothetically changed and it has been found that they have no significant effect on overall ranking which preserves its current order. However, it is not the same in case of 'Performance'. If the decision makers assign extremely high priority to performance factors and ignore all other factors, the ranking is reversed with CFCPP at top of the list and Waste Heat Recovery CPP and the RDF being the second and third respectively. This is because of the reason that performance of the CF-CPP seems slightly better than others. This hypothetical scenario is shown in Fig. 6.

APPENDIX-I: FUZZY AND NORMALIZED WEIGHTS OF OBJECTIVE SUB-FACTORS WITH RESPECT TO ALTERNATIVES

\begin{tabular}{|c|c|c|c|c|c|c|}
\hline Factors & Alternatives & Fuzzy Value & Fuzzy Rating & $\begin{array}{c}\text { Defuzzified } \\
\text { Weight }\end{array}$ & $\begin{array}{c}\text { Normalized } \\
\text { Weight }\end{array}$ & Data Source \\
\hline \multirow{3}{*}{$\begin{array}{l}\text { Initial Cost } \\
\text { (Million \$) }\end{array}$} & WHR & $(30,45,60)$ & $(2.25,3,4.5)$ & 3.1250 & 0.2899 & \multirow{3}{*}{$\begin{array}{l}\text { Calculated from Financial and Technical Reports of } \\
\text { renowned cement firms of Pakistan, [31], Reports } \\
\text { from CEWEP (Confederation of European } \\
\text { Waste to Energy Plants) URL:http://www.cewep.eu/, } \\
\text { [32], Data collected from different reports available } \\
\text { at Ekokem URL:http://www.ekokem.com/en/ }\end{array}$} \\
\hline & $\mathrm{CF}$ & $(30,47.5,65)$ & $(2.08,2.84,4.5)$ & 2.9909 & 0.2775 & \\
\hline & $\mathrm{RDF}$ & $(27,29,31)$ & $(4.35,4.66,5)$ & 4.6626 & 0.4326 & \\
\hline \multirow{3}{*}{$\begin{array}{l}\text { O\&M Cost } \\
\text { (USD) }\end{array}$} & WHR & $(900,1837,1875)$ & $(2.4,2.45,5)$ & 2.8660 & 0.4405 & \multirow{3}{*}{$\begin{array}{l}\text { Reports provided by Alternative Energy } \\
\text { Development Board of Pakistan, } \\
\text { URL:http:/www.aedb.org/ }\end{array}$} \\
\hline & $\mathrm{CF}$ & $(2475,3237,000)$ & $(1.13,1.39,1.82)$ & 1.4172 & 0.2178 & \\
\hline & $\mathrm{RDF}$ & $(1950,2025,2100)$ & $(2.14,2.22,2.31)$ & 2.2232 & 0.3417 & \\
\hline \multirow{3}{*}{$\begin{array}{c}\mathrm{CO}_{2} \text { Emission } \\
\text { (lb/MWh) }\end{array}$} & WHR & $(1,1,1)$ & $(5,5,5)$ & 5 & 0.9984 & \multirow{3}{*}{$\begin{array}{c}\text { Calculated from Financial and Technical Reports of } \\
\text { renowned cement firms of Pakistan, } \\
\text { http://www.epa.gov/cleanenergy/energy and } \\
\text { you/affect/air-emissions }\end{array}$} \\
\hline & $\mathrm{CF}$ & $(2249,2249,2249)$ & $(0,0,0)$ & 0.0022 & 0.0004 & \\
\hline & $\mathrm{RDF}$ & $(837,837,837)$ & $(0.01,0.01,0.01)$ & 0.0060 & 0.0012 & \\
\hline \multirow{3}{*}{$\begin{array}{c}\text { NO }_{\mathrm{x}} \text { Emission } \\
(\mathrm{b} / \mathrm{MWh})\end{array}$} & WHR & $(1,1,1)$ & $(5,5,5)$ & 5 & 0.7397 & \multirow{3}{*}{$\begin{array}{c}\text { Calculated from Financial and Technical Reports of } \\
\text { renowned cement firms of Pakistan, } \\
\text { http:/www.epa.gov/cleanenergy/energy-and } \\
\text { you/affect/air-emissions }\end{array}$} \\
\hline & $\mathrm{CF}$ & $(6,6,6)$ & $(0.83,0.83,0.83)$ & 0.8333 & 0.1233 & \\
\hline & $\mathrm{RDF}$ & $(5.4,5.4,5.4)$ & $(0.93,0.93,0.93)$ & 0.9259 & 0.1370 & \\
\hline \multirow{3}{*}{ Efficiency } & WHR & $(20,25,30)$ & $(2.08,2.6,3.13)$ & 2.6042 & 0.2942 & \multirow{3}{*}{$\begin{array}{l}\text { Calculated from Financial and Technical Reports of } \\
\text { renowned cement firms of Pakistan } \\
\text { Comparison of power plant efficiencies extracted } \\
\text { from information available at } \\
\text { http:/www.brighthubengineering. } \\
\text { com/power plants,[33] }\end{array}$} \\
\hline & $\mathrm{CF}$ & $(32,40,48)$ & $(3.33,4.17,5)$ & 4.1667 & 0.4706 & \\
\hline & $\mathrm{RDF}$ & $(15,20,25)$ & $(1.56,2.08,2.6)$ & 2.0833 & 0.2353 & \\
\hline \multirow{3}{*}{$\begin{array}{l}\text { Life Time } \\
\text { (Years) }\end{array}$} & WHR & $(20,25,30)$ & $(3.33,4.17,5)$ & 4.1667 & 0.3704 & \multirow{3}{*}{$\begin{array}{l}\text { Calculated from Financial and Technical Reports of } \\
\text { renowned cement firms of Pakistan } \\
\text { Reports from CEWEP URL:http:/www.cewep.eu/, } \\
\text { [32], Data collected from different reports } \\
\text { available at EkokemURL:http:// } \\
\text { www.ekokem.com/en/[34] }\end{array}$} \\
\hline & $\mathrm{CF}$ & $(20,22.5,25)$ & $(3.33,3.754 .17)$ & 3.75 & 0.3333 & \\
\hline & $\mathrm{RDF}$ & $(15,20,25)$ & $(2.5,3.33,4.17)$ & 3.3333 & 0.2963 & \\
\hline \multirow{3}{*}{ Availability } & WHR & $(80,89.5,99)$ & $(4.04,4.52,5)$ & 4.5202 & 0.3456 & \multirow{3}{*}{ www.wikipedia.org/wiki/ Availability_factor } \\
\hline & $\mathrm{CF}$ & $(70,80,90)$ & $(3.54,4.04,4.55)$ & 4.0404 & 0.3089 & \\
\hline & $\mathrm{RDF}$ & $(80,89.5,99)$ & $(4.04,4.52,5)$ & 4.5202 & 0.3456 & \\
\hline
\end{tabular}

Mehran University Research Journal of Engineering \& Technology, Volume 36, No. 4, October, 2017 [p-ISSN: 0254-7821, e-ISSN: 2413-7219] 


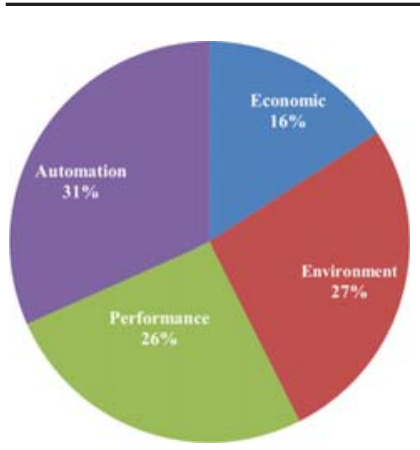

(a) WEIGHTS OF MAIN FACTORS

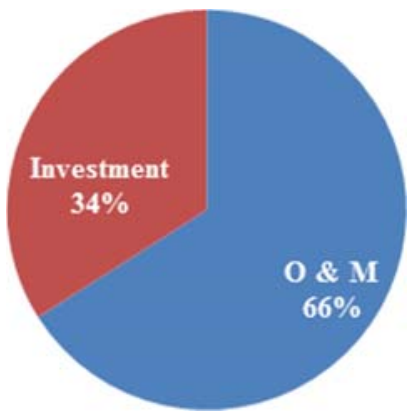

(b) ECONOMIC SUB-FACTORS

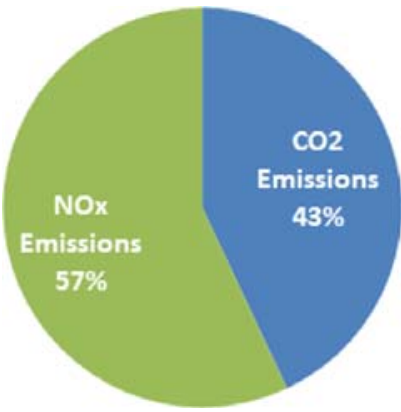

(c) ENVIRONMENT SUB-FACTORS

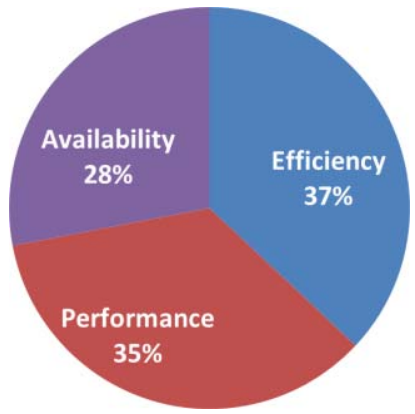

(d) PERFORMANCE SUB-FACTORS

FIG. 3. FACTORS WEIGHTS

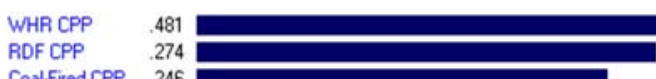

Coal.Fired CPP .246

FIG. 4. CPP RANKINGS

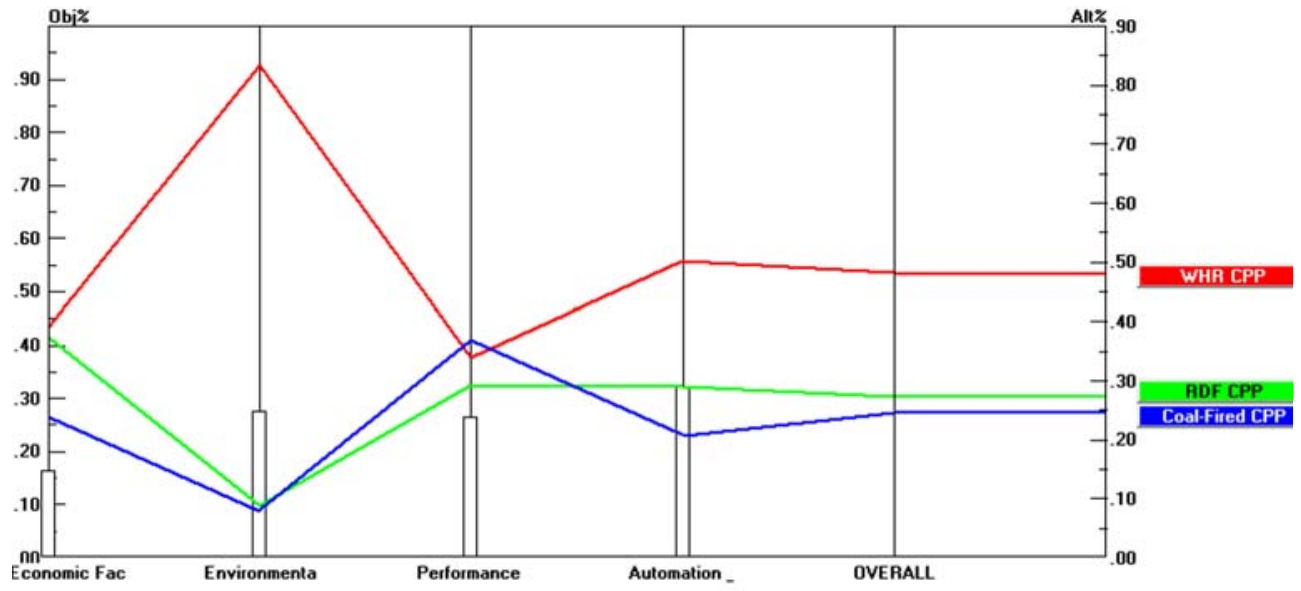

FIG. 5. PERFORMANCE OF ALTERNATIVES W.R.T CRITERIA

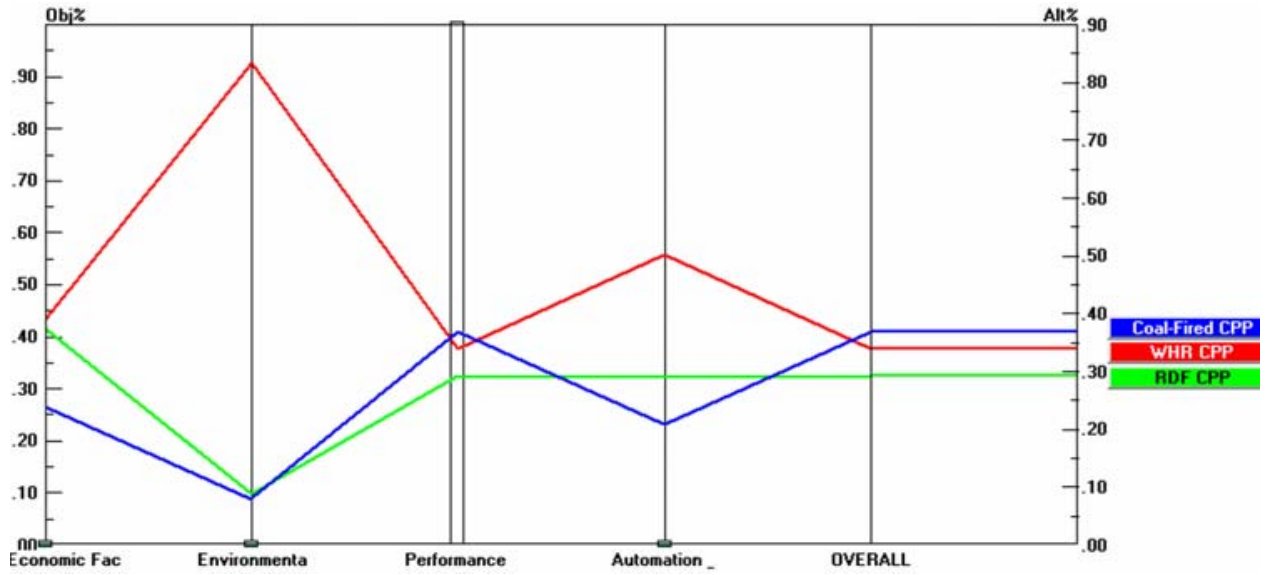

FIG. 6. HYPOTHETICAL SCENARIO OF 'PERFORMANCE FACTOR' 


\section{CONCLUSION}

Top management of the Pakistan cement industry are looking for alternative sources of electricity generation to cope with the energy deficiency. Like any other industry in the country, cement sector is also suffering from energy shortfall. Pakistan is one of the major cement producing countries and to keep its position in the world export market and attract investment in this sector there is high time to look for alternative solutions. When selecting the alternative sources for electricity generation, decision makers need to know as what weight they shall assign to factors under consideration. The present study presents an ordered and methodical analysis of the criteria influencing such decision. As per results shown in this study, decision makers of Pakistani cement industry prefer highly automated, environmentally friendly and efficient CPPs and are not much concerned about the economic factor. Even though economic factor came out as the least important, 'operations and maintenance cost' emerges as the critical sub-factor among the economic factors.

Based on priorities defined in this study, WHR-CPP stands out as the most appropriate power plant among the three alternatives which is due to its supremacy in factors like automation, environment and economy. CF-CPP is least preferred, mainly because of its hazardous nature for environment and lack in sophistication. This study is cement industry specific in the Pakistani context and results can be applied in comparable energy conditions. Similar approach can be used to find out preferences in other industries.

\section{ACKNOWLEDGEMENT}

This study is based on a research project conducted by University of Engineering \& Technology, Taxila, Chakwal Campus, Pakistan. The authors are thankful to the Industry Experts for providing their precious opinions inevitable for the completion of this study.

\section{REFERENCES}

[1] Government of Pakistan, "State of Industry Report”,National Electric Power Regulatory Authority, Islamabad, Pakistan, 2014.

[2] Government of Pakistan, "Power System Statistics 20132014”, National Transmission and Dispatch Company, Islamabad, Pakistan, 2014.

[3] Aliani, F., "Pakistan Cements”, BMA Capital Management Ltd, Karachi, Pakistan, 2013.

Raza, A., "Cement Industry: Concrete Base Appears Despite Cost Increase”, Pearl Securities Ltd, Karachi, Pakistan, 2015.

[5] Subohi, A., "Plans for Captive Power Plants in Cement Sector”, Daily Dawn,Pakistan, Herald Publications, Karachi, Pakistan, May, 2013.

Mahmood, A., Javaid, N., Zafar, A., Ali, R., Ahmed, S., and Razzaq, S., “Pakistan’s Overall Energy Potential Assessment, Comparison of LNG, TAPI and IPI Gas Projects”, Renewable and Sustainable Energy Reviews, Volume 31, pp. 182-193, 2014.

Shahid, F.,"Cement Industry”, Research Report by MM Securities Pvt. Ltd., Karachi, Pakistan, 2014.

Subohi, A., "Producing Power from Waste", Report Published by Dawn,Pakistan, Herald Publications, Karachi, Pakistan, August, 2012.

[9] Gohar, K., Jahanzaib, M., and Ali, M.K., "Consumer Preferences for Selection of Solar Home Systems in Urban Areas of Pakistan”, Meharan University Research Journal of Engineering and Technology, Volume 33, No. 4, pp. 441-448, Jamshoro, Pakistan, October, 2014.

[10] Kahraman, C., Çevik, S., Ates, N.Y., and Gülbay, M., "Fuzzy Multi-Criteria Evaluation of Industrial Robotic Systems”, Computers \& Industrial Engineering, Volume 52, No. 4, pp. 414-433, 2007.

[11] Zheng, G., Zhu, N., Tian, Z., Chen, Y., and Sun, B., "Application of a Trapezoidal Fuzzy AHP Method for Work Safety Evaluation and Early Warning Rating of Hot and Humid Environments”, Safety Science, Volume 50, No. 2, pp. 228-239, 2012. 
[12] Laarhoven, P.J.M., and Pedrycz, W., "A Fuzzy Extension of Saaty's Priority Theory”, Fuzzy Sets and System, Volume 11, pp. 229-241, 1983.

[13] Buckley, J.J., “Fuzzy Hierarchical Analysis”, Fuzzy Sets and Systems, Volume 17, No. 3, pp. 233-247, 1985.

[14] Jafarian, M.,and Vahdat, S.E., “A Fuzzy Multi-Attribute Approach to Select the Welding Process at High Pressure Vessel Manufacturing”, Journal of Manufacturing Processes, Volume 14, No. 3, pp. 250-256, 2012.

[15] Isaai, M.T., Kanani, A., Tootoonchi, M., and Afzali, H.R., "Intelligent Timetable Evaluation Using Fuzzy AHP”, Expert Systems with Applications, Volume 38, No. 4, pp. 3718-3723, 2011.

[16] Gao, L., and Hailu, A., "Evaluating the Effects of Area Closure for Recreational Fishing in a Coral Reef Ecosystem: The Benefits of an Integrated Economic and Biophysical Modeling”, Ecological Economics, Volume 70, No. 10, pp. 1735-1745, 2011.

Hsu, Y.G., Tzeng, G.H., and Shyu, J.Z., “Fuzzy Multiple Criteria Selection of Government Sponsored Frontier Technology R\&D Projects”, R\&D Management, Volume 33, No. 5, pp. 539-551, 2003.

[18] Wang, Y.M., Luo, Y., and Hua, Z., "On the Extent Analysis Method for Fuzzy AHP and its Applications”, European Journal of Operational Research, Volume 186, No. 2, pp. 735-747, 2008.

[19] Calabrese, A., Costa, R., and Menichini, T., “Using Fuzzy AHP to Manage Intellectual Capital Assets: An Application to the ICT Service Industry”, Expert Systems with Applications, Volume 40, No. 9, pp. 3747-3755, 2013.

[20] Lee, S.K., Mogi, G., and Kim, J.W., "Decision Support for Prioritizing Energy Technologies Against High Oil Prices: AFuzzy Analytic Hierarchy Process Approach”, Journal of Loss Prevention in the Process Industries, Volume 22, No. 6, pp. 915-920, 2009.
Choudhary, D., and Shankar, R., “An STEEP-Fuzzy AHPTOPSIS Framework for Evaluation and Selection of Thermal Power Plant Location: A Case Study from India”, Energy, Volume 42, No. 1, pp. 510-521, 2012.

[22] Kahraman, C., and Kaya, Ý., “A Fuzzy Multicriteria Methodology for Selection Among Energy Alternatives”, Expert Systems with Applications, Volume 37, No. 9, pp. 6270-6281, 2010.

[23] Tasri, A., and Susilawati, A., "Selection Among Renewable Energy Alternatives Based on a Fuzzy Analytic Hierarchy Process in Indonesia”, Sustainable Energy Technologies and Assessments, Volume 7, pp. 34-44, 2014.

[24] Heo, E., Kim, J., and Boo, K.J., "Analysis of the Assessment Factors for Renewable Energy Dissemination Program Evaluation using Fuzzy AHP”, Renewable and Sustainable Energy Reviews, Volume 14, No. 8, pp. 2214-2220, 2010.

[25] Ali, M.K., Akhtar, K., and Jahanzaib, M., “A Hybrid Multidimensional Approach to Select a Country for Global Cement Plant Location”, Meharan University Research Journal of Engineering \& Technology, Volume 34, No. 2, pp. 155-168, Jamshoro, Pakistan, April, 2015.

[26] Ali, H.M.K., "Global Facility Location; A Hybrid Modeling Approach”, DoctoralThesis, Department of Idustrial Engineering, University of Engineering \& Technology, Taxila, Pakistan, 2015.

[27] Chou, C., "The Canonical Representation of Multiplication Operation on Triangular Fuzzy Numbers”, Computers \& Mathematics with Applications, Volume 45, No. 10, pp. 1601-1610, 2003.

[28] Chang, D.Y., "Applications of the Extent Analysis Method on Fuzzy AHP”, European Journal of Operational Research, Volume 95, No. 3, pp. 649-655, 1996.

[29] Wang, Y.M., and Elhag T.M.S., "On the Normalization of Intervals and Fuzzy Weights”, Fuzzy Sets and Systems, Volume 157, pp. 2456-2471, 2006.

[30] Chou, C.C. and Yu, K.W., "Application of a New Hybrid Fuzzy AHP Model to the Location Choice", Mathematical Problems in Engineering, 2013. 